\title{
European Analytical Column No. 44
}

\section{EuCheMS 0 \\ European Chemical Sciences \\ Division of Analytical Chemistry}

\author{
D. Thorburn Burns ${ }^{1}$ • Michael J. Walker ${ }^{2} \cdot$ Wolfgang Buchberger $^{3} \cdot$ Paul J. Worsfold $^{4}$
}

Published online: 25 April 2016

(C) Springer-Verlag Berlin Heidelberg 2016

\section{Information from the EuCheMS Division of Analytical Chemistry (DAC)}

The highlight of DAC's activities in 2015 was Euroanalysis XVIII, held in Bordeaux, France, 6-10 September. This conference was perfectly organized by the French Chemical Society with Philippe Garrigues and Christian Rolando as co-chairs and attracted around 700 participants from 56 countries. It was also a worthy venue for presenting the prestigious Merck Award to Petra Dittrich (ETH Zurich, Switzerland) and the recently established DAC-EuCheMS Award to Miguel Valcárcel (University of Cordoba, Spain). The Robert Kellner Lecture was delivered by Bernhard Lendl.

Bordeaux was also the venue for the 46th Meeting of DAC on 6 September 2015. On this occasion the DAC Tribute was awarded to Reiner Salzer in recognition of his

Wolfgang Buchberger

wolfgang.buchberger@jku.at

D. Thorburn Burns

d.t.burns@qub.ac.uk

Michael J. Walker

michael.walker@1gcgroup.com

Paul J. Worsfold

pworsfold@plymouth.ac.uk

1 Institute for Global Food Security, The Queen's University of Belfast, Belfast BT9 5HN, UK

2 Laboratory of the Government Chemist, Teddington TW11 0LY, UK

3 Analytische Chemie, Universität Linz, Altenbergerstrasse 69, 4040 Linz, Austria

4 School of Geography, Earth and Environmental Sciences, Plymouth University, Plymouth PL48AA, UK longstanding commitment to the Division of Analytical Chemistry (DAC) of EuCheMS and the advancement of analytical chemistry in Europe. In 2016, DAC is chaired by Paul Worsfold (UK). The delegates unanimously adopted the nomination of Slavica Razic (Serbia) as chair elect. She will be chair of DAC for 2017-2019. The other members of the steering committee for 2016 are Wolfgang Buchberger (Austria), Jiri Barek (Czech Republic), Christian Rolando (France), Charlotta Turner (Sweden) and Sibel Özkan (Turkey). A meeting of the steering committee has been scheduled for April 2016 in Stockholm to discuss ongoing activities as well as the preparations for Euroanalysis XIX to be held in this city from 28 August to 1 September 2017 (information is provided at http:// euroanalysis2017.se). Please make a note of this date. We can expect to see another premier European meeting in analytical chemistry that constitutes a broad forum for scientists from academia, the public sector and industry.

At the annual meeting in Bordeaux the delegates also voted unanimously in favor of Istanbul as the venue for Euroanalysis XX in 2019.

Major activities of DAC are carried out within its study groups dealing with topics of particular importance in analytical chemistry, namely "Education in Analytical Chemistry", "Bioanalytics", "History", "Quality Assurance", "Chemometrics" and "Analytical Chemistry in Archaeology and Cultural Heritage". Besides, in 2015, a "Nanoanalytics" task force was been established for 1 year. Information about ongoing activities of DAC can be found on its website at www.euchems.eu/divisions/ analytical-chemistry/.

DAC encourages you to participate in the 6th EuCheMS Chemistry Congress in Seville, 11-15 September 2016 (http://euchems-seville2016.eu). The scientific programme is structured into horizontal major 
themes, one of them being "Physical, Analytical and Experimental Methods in Chemistry". Within this congress DAC will hold its next annual meeting on 11 September 2016.

In this European Analytical Column, D. Thorburn Burns and Michael J. Walker provide a personal view on one of the roles of history in analytical chemistry.

\section{The role of knowledge of the history of analytical chemistry for academics and for law enforcement authorities}

The DAC History Study Group arose as a result of earlier activities in the field by Professors Ronald Belcher and Hans Malissa; these were formalised by the establishment of the group in 1994 with Hans Malissa as chair and J. A. PerezBustamante as co-chair. Their first task was to prepare an account of the first 25 years of the Working Party on Analytical chemistry, published in 1999 [1].

The stated objectives of the group are to study and publish accounts of the history of analytical chemistry in Europe with reference to individual countries, specific locations, techniques, applications, professional bodies and personalities. One primary way to achieve this, and be consistent with the rules for EUROANALYSIS, has been to promote and support a plenary or keynote lecture on the material relevant to the host country at each EUROANALYSIS conference, and ensure its subsequent publication. With the exceptions of EUROANALYSIS I, XII and XV held respectively in Heidelberg, Dortmund and Innsbruck, this aim has been achieved. As detailed accounts for Austria were provided at EUROANALYSIS VII (Vienna) and at the 80th birthday conference for Hans Malissa, held in Vienna, 2000, no further account was deemed necessary to be given in Innsbruck. No historical review lecture was given at either of the two EUROANALYSIS conferences held in Germany, because it was regarded as a nearly impossible task to achieve within the time frame available of an opening ceremony. This omission has recently been dealt with, after 12 years of concerted effort by members of the Study Group, by the publication of a wellillustrated monograph, Important Figures of Analytical Chemistry from Germany [2].

In many cases extension studies have followed on from earlier plenary or keynote lectures, with more detailed treatments of particular items, or with items omitted earlier. The greatest number of these concern topics on the history of chemistry in Belgium, Ireland, Italy and the UK. References to the plenary and keynote lectures and the publications arising from the additional studies are listed on the DAC website along with the papers arising from other conferences in the field, organised by the division or its predecessor and those held in cooperation with the International Conference on
History of Chemistry series. The output, generated over 20 years, comprises of some 53 papers, two monographs and one conference proceedings volume [3].

The justification for DAC to support a study group for the history of analytical chemistry is twofold:

1. To assist the probity and transparency of publications For academics and other researchers, a good knowledge of prior work in one's field is essential to efficient working and publication of current work in a fair and transparent manner. There are numerous recent examples of papers being published with seriously defective literature searches which give false implications of originality. Two examples, selected at random, are (a) a paper on the flow injection determination of hydrogen peroxide with immobilised peroxidase which omits at least two papers with 20-year priorities of the concepts and (b) a paper on SERS with an even shorter time interval, 8 years between it and a key prior paper. For both papers the omitted references could have been readily found by simple literature searches. It is time that editors retake the responsibility and exert sufficient effort to ensure the accuracy of priority or implied priorities made in their journals.

2. To ensure future preparedness

Awareness of history as an aid to prediction of future problems is a well-known concept; "Those who don't know history are doomed to repeat it" has been attributed to various authors such as Edmund Burke and Winston Churchill but without references. The equivalent phrase, "Those who cannot remember the past are condemned to repeat it", by George Santayana, is well documented [4].

These two reasons are illustrated by striking examples of the utility of historical salience for the analytical chemistry of food fraud and food safety herein, with particular relevance to food law enforcement.

\section{Food safety}

A valuable review [5] of chemical contamination of food and animal feed from the nineteenth century to the present day, with their health, socioeconomic, environmental and political sequelae illustrates well the recurring nature of such unfortunate events.

Recent examples include the 2008 pork dioxin crisis which was a catastrophe for the agrifood sector in Ireland $[6,7]$. Its origin was animal feed contaminated with dioxins via an apparently obscure, possibly criminally fostered route. However, the root cause was an entirely predictable and hence potentially avoidable repeat of events in Belgium in 1999 [8].

Antibiotic residues in foods are another regularly reoccurring issue with severe health implications [5]. A review 
of historical and current problems in official analyses for nitrofuran residues in farmed prawns gave rise to a detailed consideration of the forensic issues involved with actual or apparent contamination and recommendations for best practice in such analyses of the edible portions [9]. These recommendations are cited in the current extensive review by the European Food Safety Authority (EFSA) [10].

The use of a wide range of illegal dyes to improve food appearance is also highly repetitive on an historical scale and has led to the development of a screening method to detect the presence of those most commonly used (Burn et al., in preparation).

\section{Food fraud}

As the recent European horse meat episode [11] has shown, historical frauds rearise with depressing regularity causing massive loss of consumer confidence with significant economic consequences. This particular species substitution was not a new problem in the UK, for in 1886 a question was raised in the UK parliament about diseased horses being shipped to Rotterdam for slaughter for human consumption and "...re-shipped to this country in the form of sausages and tinned meats" [12]. Following this debate the Sale of Horseflesh \&c Regulation Act 1889 [13] required that the sale of horseflesh for human consumption be disclosed by way of a sign "....in legible characters of not less than 4 inches in length and so as to be visible throughout the whole time". The act created the offence of supplying horseflesh when another meat was asked for or including horse in a compound article of food which is not ordinarily made of horseflesh. Prior to the recent problem of meat species substitution in Europe, the 1981 "great meat substitution scandal" in Australia, stemming from the detection of horse meat in Australian beef shipped to a plant in San Diego in the USA [14], should have put European food authorities on alert to the possibility of its reoccurrence. In the 1981 Australian event considerable quantities of pet food had been illegally diverted into the human food chain and beef sold as Halal food, which had not been slaughtered according to Islamic practice.

The review of the history of food authenticity in Belgium and the UK, with reference to butter and margarine, again indicated that several lessons for the twenty-first century in the field of edible oils and fats could be learnt from a knowledge of prior adverse events [15].

\section{Conclusions}

(i) A full comprehensive literature search is an essential prerequisite for the transparent and truthful reporting of scientific research. (ii) Active review and high salience of prior adverse events coupled with advances in measurements and their interpretation are among the best defences against repetition of contamination and fraudulent adulteration of food in their modern variants.

(iii) The current challenge is to ensure that those with an appreciation of history and those involved with research and law enforcement communicate effectively.

(iv) A review of readily available sources of references prior to the time period now covered by Chemical Abstracts and SciFinder would be timely.

\section{References}

1. Burns DT, Gogola A, Malissa H, Ninistö L, editors. 25 years of the Working Party on Analytical Chemistry of the Federation of European Chemical Societies, 1972-1997. Ljubljana: Slovenian Chemical Society; 1999.

2. Burns DT, Müller RK, Salzer R, Werner G. Important figures of analytical chemistry from Germany in brief biographies: from the middle ages to the twentieth century. Heidelberg: Springer; 2015.

3. Burns DT. Contributions to the history of AC in Europe. DAC History study group. http:/www.euchems.eu/wp-content/uploads/ 2011/03/DAC_Contributions_to_the_History_of_AC_in_Europe. pdf. Accessed 14 Apr 2016.

4. Santayana G. Reason in common sense. London: Constable; 1906, p. 284.

5. Thomson B, Poms R, Rose M. Incidents and impacts of unwanted chemicals in food and feeds. Qual Ass Safety Crops Foods. 2012;4: 77-92.

6. Marnane I. Comprehensive environmental review following the pork $\mathrm{PCB} /$ dioxin contamination incident in Ireland. J Enviro Monit. 2012;14:2551-6.

7. MacKenzie KJ. Independent review of the dioxin incident in Northern Ireland, December 2008. N I Exec Belfast; 2010.

8. Covaci A et al. The Belgian PCB/dioxin crisis- 8 years later: an overview. Environ Toxicol Pharmacol. 2008;25:164-70.

9. Points J, Burns DT, Walker MJ. Forensic issues in the analysis of trace nitrofuran veterinary residues in food of animal origin. Food Control. 2014;50:92-103.

10. EFSA Panel on Contaminants in the Food Chain. Scientific opinion on nitrofurans and their metabolites in the food chain. EFSA J. 2015;13(6):4140, pp. 217.

11. Walker MJ, Burns M, Burns DT. Horse meat in beef products species substitution 2013. J Assoc Public Analysts. 2013;41:67-106.

12. Hansard, HC Deb 07 May 1896, vol 40, cc 729-30.

13. The Sale of Horseflesh \&c Regulation Act 1889, An Act to Regulate the Sale of Horseflesh for Human Food [52 \& 53 Vict. Ch 11].

14. Woodward, AE. Report of the Royal Commission into the Australian Meat Industry. Canberra, The Australian Government Publishing Service; 1982.

15. Deelstra H, Burns DT, Walker MJ. The adulteration of food, lessons from the past, with reference to butter, margarine, and fraud. Eur Food Res Technol. 2014;239:725-44. 